\title{
NÍVEIS DE LÍPIDES PLASMÁTICOS EM RATOS SUBMETIDOS À ESPLENECTOMIA TOTAL, LIGADURA SIMULTÂNEA DOS VASOS ESPLÊNICOS E À ESPLENECTOMIA SUBTOTAL COM PRESERVAÇÃO DO PÓLO INFERIOR
}

\author{
PLASMATIC LIPIDS LEVELS IN RATS AFTER TOTAL SPLENECTOMY, SIMULTANEOUS \\ LIGATURE OF THE SPLENIC VESSELS AND SUBTOTAL SPLENECTOMY WITH \\ INFERIOR POLE PRESERVATION
}

\author{
Isabel Cristina Andreatta Lemos Paulo, ACBC-MG'; ; Danilo Nagib Salomão Paulo,TCBC-MG²; \\ Alcino Lázaro da Silva, TCBC-MG ${ }^{3}$; Rodrigo Moulin Foletto ${ }^{4}$; Geraldo Luiz Colnago ${ }^{5}$; \\ Paulo Merçon Vargas ${ }^{6}$
}

\begin{abstract}
RESUMO: Objetivo: Verificar o efeito da esplenectomia total, da ligadura dos vasos esplênicos principais e da esplenectomia subtotal com preservação do pólo inferior, nos lípides plasmáticos de ratos alimentados com dieta-controle ou dieta acrescida com 2,5\% de colesterol. Método: Foram utilizados 111 ratos Wistar, machos, pesando entre $273 \mathrm{~g}$ e $427 \mathrm{~g}$, com idade aproximada de 12 semanas, assim distribuídos : Grupo 1, controle ( $\mathrm{N}=20)$, não operado; Grupo $2(\mathrm{~N}=20)$ submetido à manipulação do baço; Grupo 3 $(\mathrm{N}=31)$ submetido à esplenectomia total; Grupo $4(\mathrm{~N}=20)$, ligadura simultânea da artéria e veia esplênicas; Grupo $5(\mathrm{~N}=20)$, esplenectomia subtotal com preservação do pólo inferior. Foram dosados os lípides plasmáticos, e os ratos foram distribuídos em dois subgrupos, de acordo com a dieta (Subgrupo A- dieta-controle; Subgrupo B- dieta acrescida com 2,5\% de colesterol). Todos os animais foram submetidos à nova colheita de sangue após 90 dias do início do experimento. Resultados: Os animais submetidos à esplenectomia total, independentemente do tipo de dieta, apresentaram aumento significante $(\mathrm{p}<0,05)$ do colesterol total, LDL, VLDL e triglicérides. $\mathrm{O}$ aumento da HDL foi significante nos ratos alimentados com dieta-controle $(\mathrm{p}<0,05)$ e não significante nos alimentados com dieta acrescida com $2,5 \%$ de colesterol $(\mathrm{p}>0,05)$. Os animais submetidos à ligadura simultânea da artéria e veia esplênicas e à esplenectomia subtotal com preservação do pólo inferior e alimentados com dieta-controle, não apresentaram alterações nos níveis de lípides plasmáticos, exceto pelo aumento da HDL $(\mathrm{p}<0,05)$ observado no grupo da esplenectomia subtotal. Nos animais desses grupos, alimentados com dieta acrescida com 2,5\% de colesterol, houve aumento significante de colesterol total, LDL, e VLDL e triglicérides. Conclusões: A esplenectomia total produz aumento significante do colesterol total, das fraç̃oes LDL e VLDL e dos triglicérides, tanto nos ratos alimentados com dieta-controle quanto nos alimentados com dieta acrescida com 2,5\% de colesterol. O aumento é mais significante nos animais alimentados com dieta acrescida com 2,5\% de colesterol. A ligadura simultânea da artéria e veia esplênicas e a esplenectomia subtotal com preservação do pólo inferior previnem contra as alterações dos níveis de lípides plasmáticos observadas em ratos submetidos à esplenectomia total alimentados com dieta-controle ou acrescida com 2,5\% de colesterol (Rev. Col. Bras. Cir. 2005; 32(5): 229-236).
\end{abstract}

Descritores: Baço/metabolismo; Esplenectomia/efeitos adversos; Esplenectomia/métodos; Artéria esplênica; Veia esplênica; Ligadura.

\section{INTRODUÇÃO}

A esplenectomia total pode provocar complicações, entre as quais a sepse fulminante ${ }^{1-3}$ destacada por King e Shumacker ${ }^{4}$, em 1952, observada em $2,7 \%$ dos esplenectomizados ${ }^{5}$ e também em animais de experimentação ${ }^{6-9}$. Além disto tem sido relatadas alterações no metabolismo lipídico tanto em seres humanos ${ }^{10-12}$ quanto em animais de experimentação ${ }^{13-16}$ que podem provocar aterosclerose ${ }^{13}$. Por essas razões têm sido cada vez mais valorizadas as operações conservadoras sobre o baço, que incluem as ligaduras vasculares e as esplenectomias parciais. A ligadura da artéria esplênica é realizada como coadjuvante do tratamento do trauma esplênico ${ }^{17}$, no combate à hipertensão $\operatorname{porta}^{18}$ e no aneurisma da artéria esplênica ${ }^{19}$. Experimentalmente, em ratos normais, a ligadura da artéria esplênica reduz a massa funcional do baço ${ }^{20}$, combate o hiperesplenismo induzido por ligadura da veia esplênica ${ }^{20,21} \mathrm{e}$ a hipertensão porta experimen$\operatorname{tal}^{22}$, aumenta a susceptibilidade à infecção por pneumococo, quando comparada a um grupo simulação ${ }^{23}$ e diminui a morta-

1. Médica do Hospital Universitário Cassiano Antonio Morais da Universidade Federal do Espírito Santo; Mestre em Cirurgia pela Faculdade de Medicina da Universidade Federal de Minas Gerais (UFMF).

2. Professor Titular da Disciplina de Técnica Operatória e Cirurgia Experimental da Escola Superior de Ciências da Santa Casa de Misericórdia de Vitória-ES-EMESCAM.

3. Professor Titular de Cirurgia da Faculdade de Medicina da Universidade Federal de Minas Gerais.

4. Residente de Cirurgia da Santa Casa de Misericórdia de Vitória-ES

5. Professor Adjunto de Nutrição Animal da Faculdade de Veterinária da Universidade Federal Fluminense-Niterói- RJ.

6. Professor de Patologia da Universidade Federal do Espírito Santo

Recebido em: 18/02/2005

Aceito para publicação em: 23/08/2005

Conflito de interesse: nenhum

Fonte de financiamento: nenhuma

Trabalho realizado no Laboratório de Técnica Operatória e Cirurgia Experimental da Escola Superior de Ciências da Santa Casa de Misericórdia de Vitória-ES- EMESCAM; Dissertação defendida, com aprovação, na Faculdade de Medicina da UFMG em 29/11/2004. 
lidade de ratos por sepse pneumocócica quando associada à infusão de solução salina e comparada à esplenectomia ${ }^{24}$. Em cães, a ligadura de ramos da artéria esplênica contribui para indução de pancreatite aguda ${ }^{25}$, mas protege o animal de infecção por pneumococo, quando associada à exérese do polo inferior do baço ${ }^{26}$. A ligadura da artéria esplênica em coelhos diminui a resposta imune à administração intravenosa de antígenos morfologicamente modelados ${ }^{27}$. A ligadura simultânea da artéria e veia esplênicas, com preservação do baço, em seres humanos, foi realizada na pancreatectomia caudal por laparatomia ${ }^{28,29}$ e por via laparoscópica ${ }^{30}$. Relatos das consequiências para o baço de ratos dessa ligadura simultânea foram recentemente descritas ${ }^{31}$. Não encontramos na literatura, entretanto, referências sobre as repercussões dessa ligadura no metabolismo lipídico de ratos. As esplenectomias parciais foram descritas em seres humanos ${ }^{32,33}$ e em animais de experimentação ${ }^{34-36}$. Não encontramos referências sobre a esplenectomia parcial com preservação do polo inferior do baço, em ratos, mas sim em cães ${ }^{36}$ e não há descrição sobre o efeito dessa cirurgia no metabolismo lipídico de ratos. Por essas razões, planejamos estudar os efeitos da esplenectomia total, da ligadura simultânea da artéria e veia esplênicas e da esplenectomia subtotal com preservação do polo inferior sobre os níveis de lípides plasmáticos de ratos adultos, alimentados com dieta-controle ou com dieta acrescida com 2,5\% de colesterol.

\section{MÉTODO}

Os procedimentos foram aprovados pelo Comitê de Ética em Pesquisa da Escola Superior de Ciências da Santa Casa de Misericórdia de Vitória-ES .

Foram utilizados 111 ratos, Wistar, machos, com peso entre $273 \mathrm{~g}$ e $427 \mathrm{~g}$, com idade de, aproximadamente, 12 semanas. Os animais foram alocados em gaiolas coletivas, com capacidade para seis animais, onde eram alimentados, antes do experimento, com ração comercial granulada para animais de laboratório (Moinho Primor MP-77, São Paulo). Os ratos foram distribuídos aleatoriamente em cinco grupos: Grupo 1-20 animais, controle (não operado); Grupo 2-20 animais, simulado (manipulação esplênica); Grupo 3 - 31 animais, esplenectomia total; Grupo 4 - 20 animais, ligadura simultânea da artéria e da veia esplênicas com preservação do baço; Grupo 5 - 20 animais, grupo da esplenectomia subtotal com preservação do polo inferior. Após um jejum de 12 horas cada animal foi anestesiado superficialmente com vapores de éter etílico e submetido à punção cardíaca transtorácica, para colheita de 1,2 mL de sangue e dosagem dos lípides plasmáticos (colesterol total, HDL, LDL, VLDL e triglicérides). A seguir foram pesados (balança eletrônica Filizola -sensibilidade de 1 g), identificados com marca na orelha e devolvidos às suas gaiolas de origem. A dosagem dos lípides foi feita no aparelho Dimension AR DADE BEHRING, Illinois, EUA.

Iniciado o experimento, os animais do grupo 1 foram mantidos em suas gaiolas e passaram a receber dieta-controle (Subgrupo A) ou acrescida com 2,5\% de colesterol (Subgrupo $\mathrm{B})$ (Tabela 1) e água à vontade. A dieta com colesterol foi manipulada adicionando-se $25 \mathrm{~g}$ de colesterol puro a cada $\mathrm{Kg}$ de ração controle, preparada especialmente para o experimento. O colesterol puro é obtido a partir da lã de ovelhas, lanolina, importado da Holanda, gentilmente doado pela Agribrands do Brasil. As dietas foram manipuladas pela Du Milho Indústria e Comércio e fornecida a título de cortesia para a pesquisa.

Cada grupo, exceto o grupo controle, foi submetido à cirurgia proposta, conforme exposto a seguir. No Grupo 2 foi realizada apenas a manipulação do baço; no Grupo 3 foi realizada a esplenectomia total com três ligaduras rentes ao baço que permitiram a secção dos vasos e a retirada desse órgão ;

Tabela 1 - Dietas utilizadas nos Subgrupos A e B. Composição centesimal da ração basal para ratos.

\begin{tabular}{lr}
\hline Ingredientes & \multicolumn{1}{c}{$\%$} \\
\hline Milho moído & 54,90 \\
Farelo de soja, 45\% & 29,00 \\
Farelo de Trigo 15\% & 10,00 \\
Óleo de soja & 2,50 \\
Fosfato bicálcico, 18\% & 1,60 \\
Calcário, 38\% & 1,34 \\
Sal comum(Cloreto de sódio) & 0,40 \\
DI-metionina,99\% & 0,11 \\
Suplemento mineral & 0,05 \\
L-Lisina.Hcl,78\% & 0,03 \\
Cloreto de colina,60\% & 0,03 \\
BHT(anti-oxidante) & 0,01 \\
Total & 100,00
\end{tabular}

Composição Química proximal

Energia metabolizável, Kcal/Kg

Proteína Bruta, \%

$3.000,00$

Fibra bruta, $\%$

19,00

Gordura, \%

4,40

Matéria mineral, \%

5,00

Cálcio, \%

6,10

Fósforo total, \%

1,00

Metionina, \%

0,70

Aminioácidos sulfurados, \% $\quad 0,76$

Lisina, $\% \quad 1,00$

Triptofano, \% $\quad 0,24$

Treonina, $\% \quad 0,72$

Arginina, \% $\quad 1,26$

Valina, $\% \quad 1,01$

Isoleucina, \% $\quad 0,94$

Histidina, $\% \quad 0,48$

Fenilalanina, \% $\quad 0,96$

Suplemento mineral: fornece por $\mathrm{Kg}$ de ração em $\mathrm{mg}$ : Ferro 40; Zinco 60; Cobre 16; Manganês 20; Iodo 50; Selênio 0,25.

Suplemento vitamínico:fornece por $\mathrm{Kg}$ de ração: vitamina A $7000 \mathrm{UI}$; Vitamina D3 $1000 \mathrm{UI}$; Vitamina E $30 \mathrm{mg}$; Vitamina K $1 \mathrm{mg}$; Tiamina 4 $\mathrm{mg}$; Riboflavina $4 \mathrm{mg}$; Ácido pantotênico $15 \mathrm{mg}$; Niacina $30 \mathrm{mg}$; Piridoxina $6 \mathrm{mg}$; Ácido fólico 0,5 mg; Biotina 0,15 mg; Vitamina B12 $0,01 \mathrm{mg}$.

OBS - A dieta dos animais do Subgrupo B teve a mesma composição básica. Para cada Kg de ração, foram adicionadas $25 \mathrm{~g}$ de colesterol puro(100\%), obtido da lã de ovelhas(lanolina), importado da Holanda e doado pela Agribrands do Brasil para este experimento. 

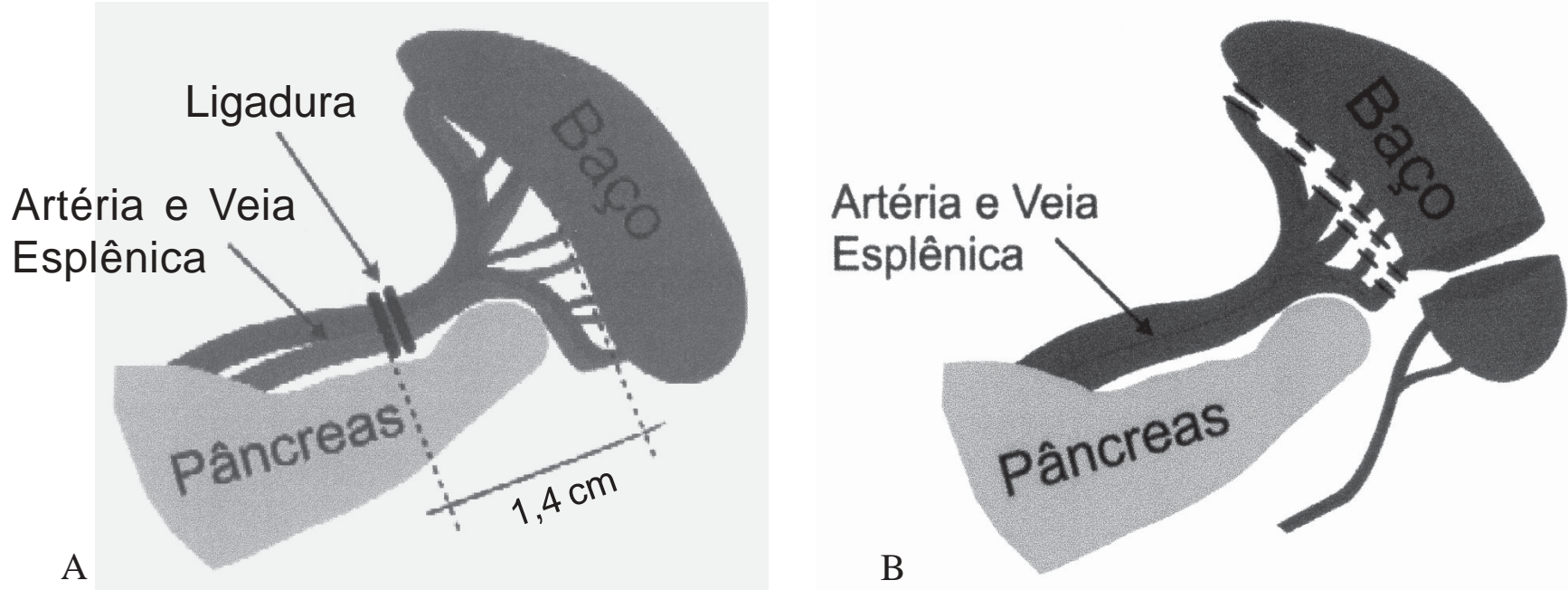

Figura 1a) Esquema mostrando os locais onde foram realizadas as ligaduras da artéria e veia esplênicas do baço de ratos, a 1,4cm da borda hilar; 1 b) Esquema mostrando as ligaduras vasculares e a secção esplênica, que permitem a esplenectomia subtotal com preservação do pólo inferior.

no Grupo 4 o baço foi rebatido para cima a fim de expor o pâncreas e identificar os vasos esplênicos. Foi realizada dupla ligadura simultânea da artéria e da veia esplênicas, a cerca de 1,4 cm da borda hilar ( Figura 1-a ), com fio mononáilon 4.0, conforme a técnica já descrita por Paulo et al. ${ }^{31}$; no Grupo 5, após a mobilização do baço, foram desvascularizadas a porção superior e média do baço, o qual foi seccionado logo abaixo dos ramos principais dos vasos esplênicos, permanecendo pediculado o polo inferior ( Figura 1-b ), de acordo com a técnica já descrita em cães ${ }^{36}$. A superfície de corte foi suturada com prolene 5.0, com dois pontos separados simples. A parede abdominal foi suturada em dois planos, com mononáilon 4.0. Após recuperação anestésica os animais foram devolvidos às suas gaiolas onde recebiam dieta-controle (Subgrupo A) ou acrescida com 2,5\% de colesterol (subgrupo B) e água à vontade. Após 90 dias foi feita nova colheita de sangue para dosagem dos lípides plasmáticos. A seguir os ratos foram mortos com dose letal de éter etílico, pesados e necropsiados. Nos animais dos grupos 1 e 2 o baço foi retirado, pesado com precisão de $0,001 \mathrm{~g}$, fotografado e fixado em formol a $4 \%$ para posterior estudo microscópico com hematoxilina-eosina. $\mathrm{O}$ mesmo foi feito com os ramanescentes esplênicos dos grupos 4 e 5 . Nos animais do Grupo 3 esse procedimento foi feito no início do experimento, na ocasião da esplenectomia.

$\mathrm{O}$ teste $\mathrm{t}$ de Student para amostras relacionadas foi utilizado para comparar os valores de pré-operatório com os de pós-operatório dos lípides plasmáticos dentro de um mesmo grupo. $\mathrm{O}$ teste t para amostras independentes foi utilizado para comparar os valores dos lípides entre grupos diferentes. O percentual médio de massa remanescente dos grupos 4 e 5 foi calculado dividindo-se o peso da porção remanescente pelo peso ideal do baço para cada animal multiplicando-se o resultado por 100. Foi obtida a média do percentual da massa viável do baço com o respectivo desvio padrão dos dois grupos. O cálculo do peso ideal do baço foi feito utilizando-se a fórmula: peso do baço $=1,80$ x peso corporal $+230,49$, obtida a partir da Análise de Regressão Linear dos pesos dos baços em função do peso corporal nos animais do grupo controle.
Um valor $\mathrm{p}<0,05$ foi considerado estatisticamente significante.

\section{RESULTADOS}

O peso médio percentual do remanescente esplênico nos animais do grupo submetido à ligadura da artéria e veia esplênicas foi 49,21\% +3,53\%, e nos animais do grupo submetido à esplenectomia subtotal com preservação do polo inferior foi $37,26 \%+3,77 \%$.

No grupo de animais esplenectomizados constatamos 11 óbitos cujas causas não foram encontradas e deiscência parcial da sutura da pele em 2 animais. Os exames da cavidade abdominal e torácica nos animais que faleceram bem como a cultura de sangue, de tecido pulmonar e hepático não identificaram a possível causa de óbito.

$\mathrm{O}$ aspecto da cavidade abdominal foi normal nos animais do Grupo 1. Nos animais dos Grupos 2 e 3 foram observadas aderências frouxas entre o baço e o estômago e o fígado e a parede abdominal.

O baço se apresentou normal em todos os casos dos Grupos 1, 2 e 3 e em três dos 20 casos do Grupo 4 (15\%). Nos demais ratos do Grupo 4 a porção superior do baço estava íntegra e havia uma formação pediculada na porção inferior desse órgão em 13 casos ou na porção média em três casos.Houve um óbito nesse grupo por evisceração. Nos animais do Grupo 5 o polo inferior ficou viável em todos os casos, com aderências vascularizadas pelo omento.

Nos animais não operados (Grupo 1), alimentados com dieta-controle ocorreu diminuição significante dos níveis de colesterol total $(\mathrm{p}<0,05)$ (Figura 2), à custa, principalmente, da fração LDL ( p<0,05) (Figura 4). Os níveis de HDL, VLDL e triglicérides (Figuras 3, 5, 6) não sofreram alterações significantes. Nos alimentados com dieta acrescida com $2,5 \%$ de colesterol houve aumento significante do colesterol total $(\mathrm{p}<0,01)$, à custa da VLDL $(\mathrm{p}<0,01)$ (Figura 5). A HDL caiu significantemente $(\mathrm{p}<0,05)$, os triglicérides aumentaram significantemente ( $\mathrm{p}<0,01$ ) (Figura 6), e o LDL não sofreu alterações significantes $(\mathrm{p}>0,05)$. 

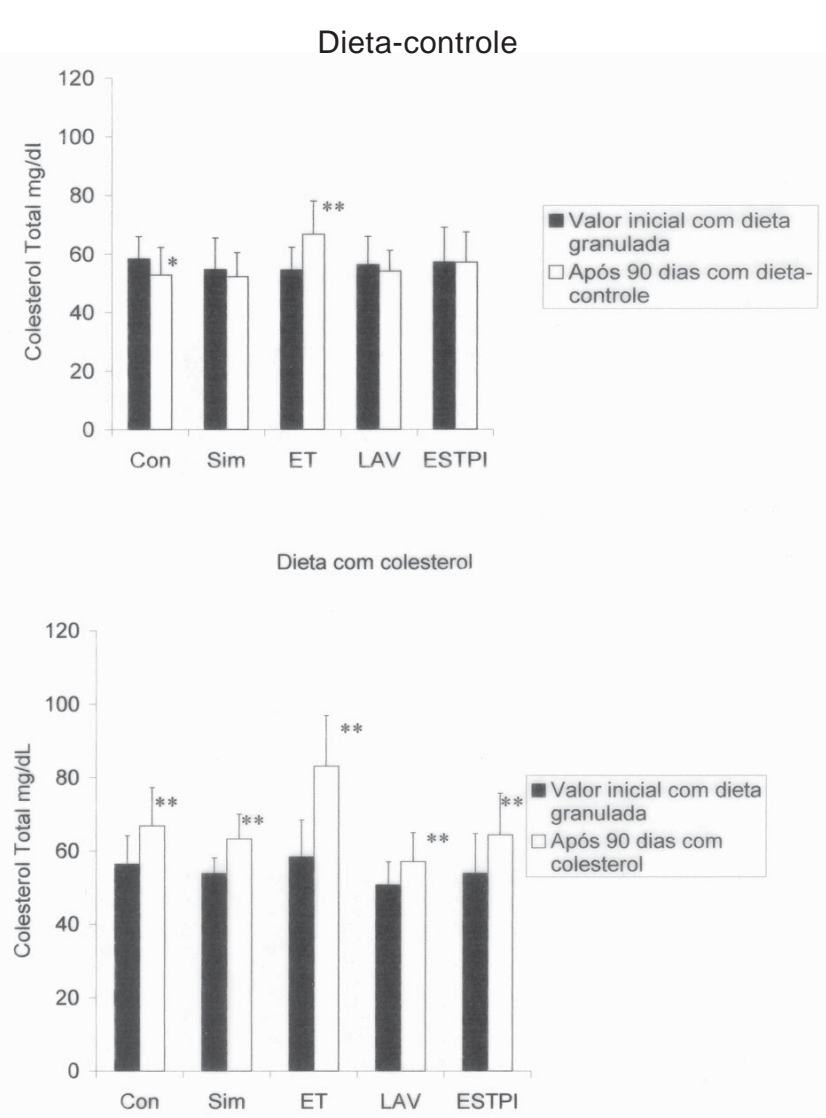

Figura 2 - Colesterol Total nos animais alimentados com dietacontrole ou com dieta acrescida com 2,5\% de colesterol. Con (Controle); Sim (Simulação); ET (Esplenectomia total); LAV (Ligadura da artéria e veia esplênicas); ESTPI (Esplenectomia subtotal com preservação do polo inferior). As colunas representam a média aritmética e desvio- padrão. ${ }^{*} p<0,05 e^{* *} p<0,01$ (Teste t de Student para amostras relacionadas).

Nos animais submetidos à manipulação do baço (Grupo 2), alimentados com dieta-controle, houve diminuição do colesterol total graças, principalmente, à queda da LDL (Figura 4). Os níveis de HDL, VLDL e triglicérides não sofreram alterações significantes. Nos alimentados com dieta acrescida com $2,5 \%$ de colesterol houve aumento significante do colesterol total ( $\mathrm{p}<0,01)$, à custa da VLDL $(\mathrm{p}<0,01)$ e da LDL $(\mathrm{p}<0,05)$. A HDL não sofreu alterações significantes. Os triglicérides aumentaram significantemente $(\mathrm{p}<0,01)$. No início do experimento, quando o grupo simulado e o grupo não operado se alimentavam com dieta granulada, não houve diferença significante nos níveis de lípides entre esses grupos. No final do experimento os níveis de colesterol total foram significantemente maiores no grupo de animais alimentados com dieta acrescida com $2,5 \%$ de colesterol $(\mathrm{p}<0,01)$, à custa da fração VLDL. Os níveis de triglicérides foram, também, significantemente maiores nos animais dos Subgrupos 1B e 2B.

Nos ratos submetidos à esplenectomia total (Grupo 3) houve aumento significante do colesterol total no pós-operatório tardio independentemente do tipo de dieta utilizada (Figura 2). Esse aumento no Subgrupo 3A ocorreu por aumento significante das três frações, e no Subgrupo 3B, graças ao aumento significante das frações LDL e VLDL (Figuras 4, 5). Houve aumento significante dos triglicérides nos dois
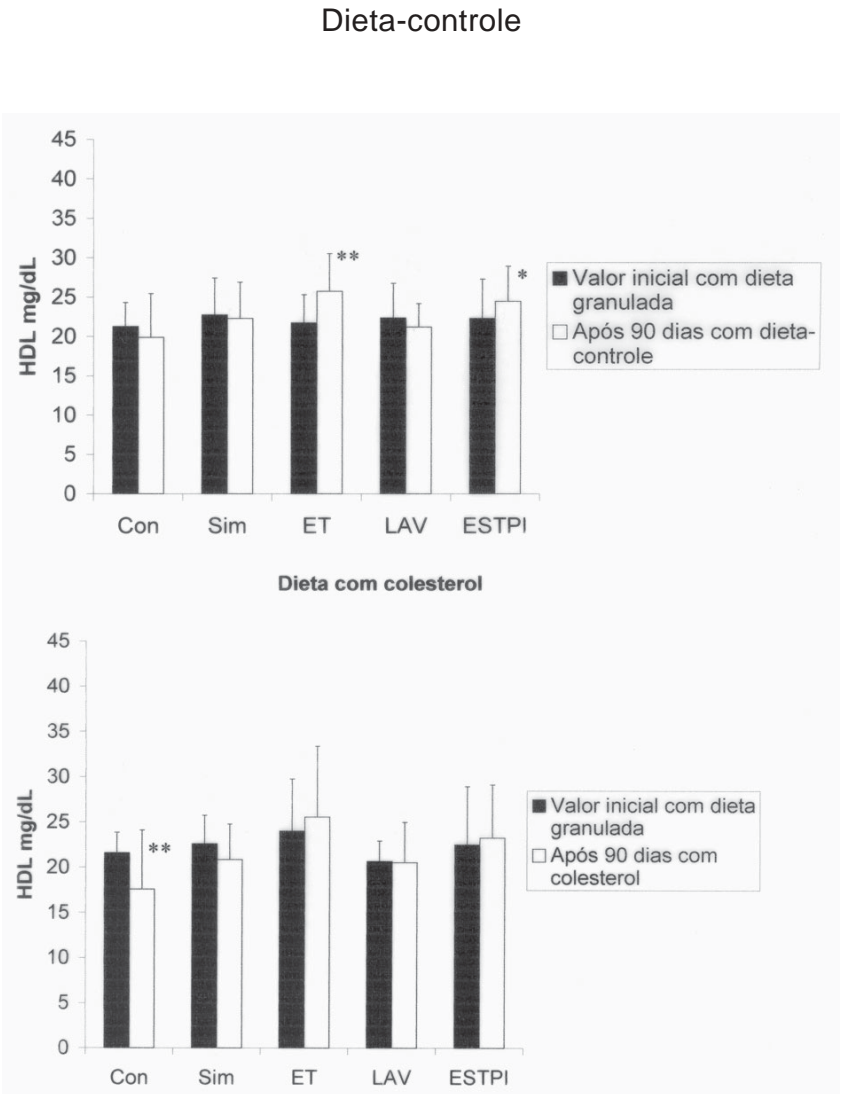

Figura 3 - HDL nos animais alimentados com dieta-controle ou com dieta acrescida com 2,5\% de colesterol. Con (Controle); Sim (Simulação); ET (Esplenectomia total); LAV (Ligadura da artéria e veia esplênicas). ESTPI(Esplenectomia subtotal com preservação do pólo inferior); As colunas representam a média aritmética e desvio- padrão. $* p<0,05 e^{* *} p<0,01$ (Teste t de Student para amostras relacionadas).

subgrupos (Figura 6). O colesterol total, LDL, VLDL e triglicérides sofreram aumento mais significante no subgrupo 3B que no 3A. No Subgrupo 3A, os níveis de colesterol total foram significantemente maiores que os do grupo não operado (Subgrupo 1A) $(\mathrm{p}<0,01)$ à custa, principalmente da HDL e da LDL. No início do experimento os níveis de VLDL e triglicérides eram maiores nos animais do grupo controle que nos animais esplenectomizados $(\mathrm{p}<0,05)$. O mesmo ocorreu no final do experimento . No Subgrupo 3B os níveis de colesterol total foram significantemente maiores que no Subgrupo 1B (não operado) $(\mathrm{p}<0,01)$. Esse aumento ocorreu à custa, principalmente, da LDL ( $p<0,01)$ e da HDL ( $p<0,05)$, no final do experimento. Não houve diferenças entre esses dois subgrupos no início do experimento. A VLDL e triglicérides não diferiram entre os dois grupos tanto no início quanto no final do experimento. Os níveis de colesterol total, independentemente da dieta utilizada, nos Subgrupos 3A e 3B foram significantemente maiores que no grupo simulação(2A, 2B) $(\mathrm{p}<0,01)$, à custa principalmente da fração LDL $(p<0,01)$. A VLDL e triglicérides não diferiram entre os dois grupos ( 2 e 3 ).

Nos animais submetidos à ligadura simultânea da artéria e veia esplênicas (Grupo 4), alimentados com dieta-controle, os níveis de colesterol no pós-operatório tardio, não sofreram variações significantes. Nos animais alimentados com 
Dieta-controle
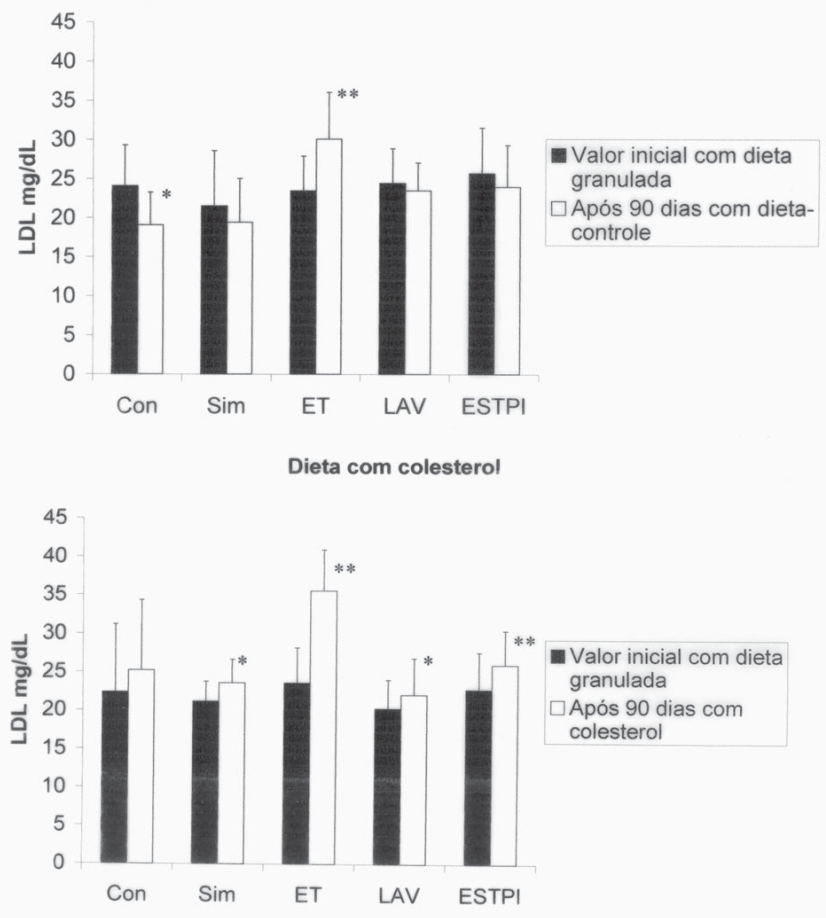

Figura 4 - LDL nos animais alimentados com dieta-controle ou com dieta acrescida com 2,5\% de colesterol. Con (Controle); Sim (Simulação); ET (Esplenectomia total); LAV (Ligadura da artéria e veia esplênicas). ESTPI(Esplenectomia subtotal com preservação do pólo inferior); As colunas representam a média aritmética e desvio- padrão. $* p<0,05 e^{* *} p<0,01$ ( Teste $t$ de Student para amostras relacionadas).

dieta acrescida com 2,5\% de colesterol, os níveis aumentaram significantemente graças ao aumento significante da VLDL $(\mathrm{p}<0,01)$ e LDL $(\mathrm{p}<0,01)$. Os triglicérides também aumentaram significantemente nesse subgrupo $(\mathrm{p}<0,01)$. Os níveis de colesterol total no grupo da ligadura foram semelhantes aos do grupo não operado, em animais alimentados com dietacontrole. A fração LDL foi significantemente maior no Subgrupo $4 \mathrm{~A}(\mathrm{p}<0,05)$, a fração VLDL no Subgrupo $1 \mathrm{~A}(\mathrm{p}<0,05)$ e a fração HDL não diferiu significantemente entre os dois subgrupos. Isso manteve os níveis de colesterol semelhantes entre os dois subgrupos. Os níveis de triglicérides foram maiores no início e no final do experimento no Subgrupo $1 \mathrm{~A}$ em relação ao 4A. Não houve alterações significantes dos triglicérides do início para o final do experimento tanto no Subgrupo 1A quanto no Subrupo 4A (Figura 6). Nos animais alimentados com dieta acrescida com 2,5\% de colesterol, as variações dos níveis de colesterol total, VLDL e triglicérides no grupo ligadura foram semelhantes aos do grupo não operado ( $\mathrm{p}<0,05)$. Os níveis de lípides no grupo da ligadura foram semelhantes ao grupo simulado, independentemente do tipo de dieta. Os níveis de colesterol total no grupo da esplenectomia total foram significantemente maiores que os níveis de colesterol total no grupo da ligadura, tanto no subgrupo 4A ( $\mathrm{p}<0,01)$ quanto no subgrupo 4B ( $\mathrm{p}<0,01)$. Nos animais alimentados com dieta-controle o aumento ocorreu graças às frações LDL e HDL, e nos alimentados com dieta acrescida com 2,5\% de colesterol, graças a LDL $(p<0,01)$ e
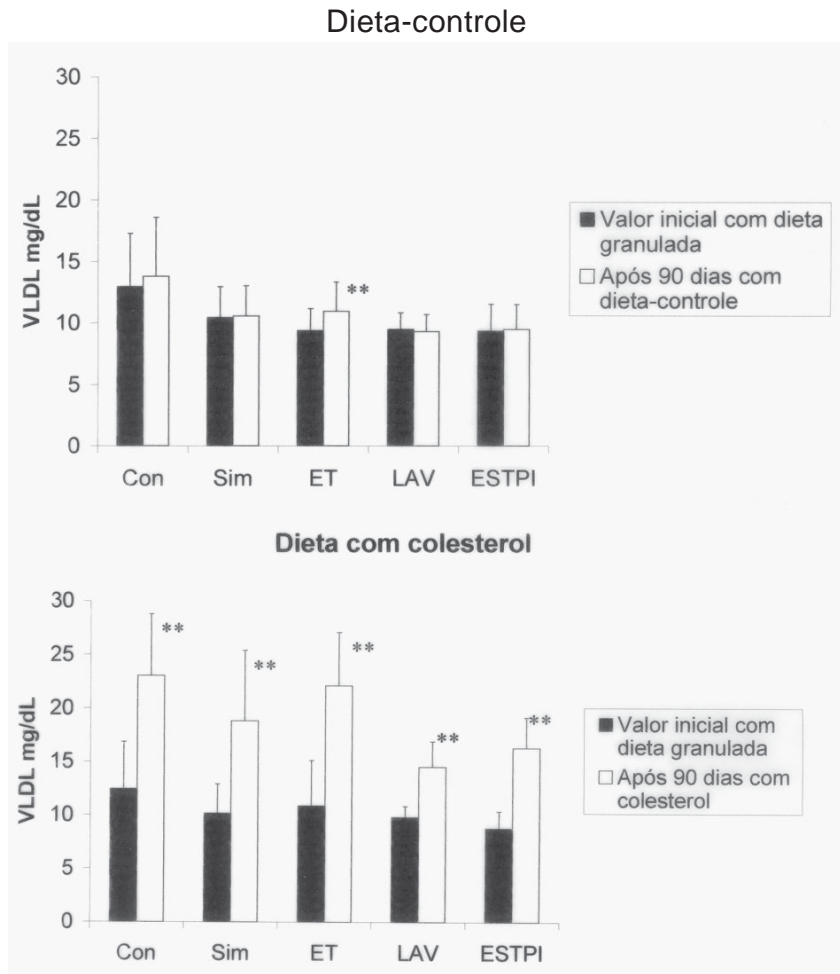

Figura 5 - VLDL nos animais alimentados com dieta-controle ou com dieta acrescida com 2,5\% de colesterol. Con (Controle); Sim (Simulação); ET (Esplenectomia total); LAV (Ligadura da artéria e veia esplênicas); ESTPI(Esplenectomia subtotal com preservação do pólo inferior). As colunas representam a média aritmética e desviopadrão. ${ }^{*} p<0,05 e^{* *} p<0,01$ (Teste $t$ de Student para amostras relacionadas).

VLDL( $p<0,01)$. Os triglicérides também foram significantemente maiores no grupo da esplenectomia total $(p<0,01)$.

Nos ratos submetidos à esplenectomia subtotal com preservação do polo inferior do baço (Grupo 5), alimentados com dieta-controle, não houve alterações dos níveis de colesterol. Houve, no entanto, aumento significante da fração HDL $(p<0,05)$ e tendência para queda da LDL $(p=0,06)$, o que equilibrou os níveis de colesterol. Nos animais alimentados com dieta acrescida com 2,5\% de colesterol houve aumento significante do colesterol graças ao aumento da fração $\operatorname{LDL}(\mathrm{p}<0,01)$ e $\operatorname{VLDL}(\mathrm{p}<0,01)$ (Figuras 4,5). Os triglicérides sofreram também aumento significante $(\mathrm{p}<0,01)$ (Figura 6). Os níveis de colesterol total desse grupo foram semelhantes aos do grupo não operado e simulado, independentemente do tipo de dieta. Os níveis de colesterol total no Subgrupo 3A tenderam a ser maiores que no Subgrupo $5 \mathrm{~A}(\mathrm{p}=0,06)$ no final do experimento, porém foram semelhantes no início do experimento. Os níveis de colesterol total no grupo da esplenectomia total, alimentados com dieta acrescida com 2,5\% de colesterol, foram significantemente maiores que no grupo da esplenectomia subtotal com preservação do polo inferior, à custa da LDL e VLDL. Os triglicérides foram também significantemente maiores no grupo da esplenectomia total. Os níveis de lipides no grupo ligadura foram semelhantes ao do grupo esplenectomia subtotal, independentemente do tipo de dieta, tanto no início quanto no final do experimento. 

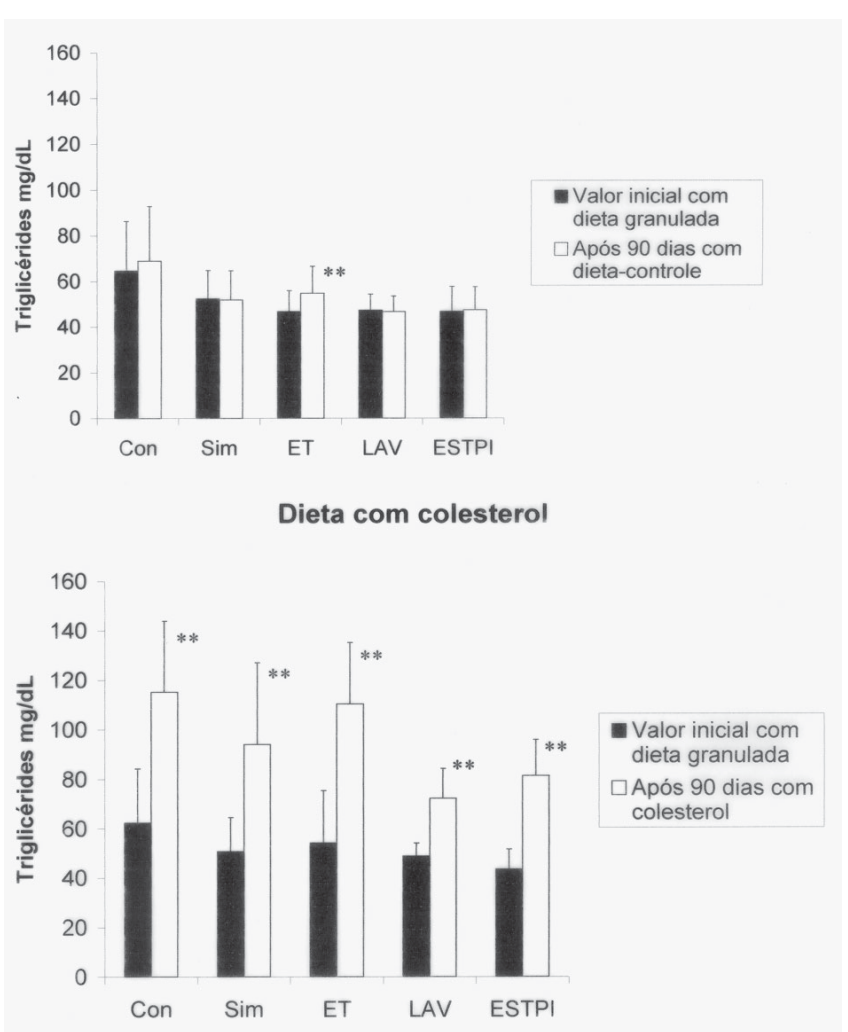

Figura 6 - Triglicérides nos animais alimentados com dieta-controle ou com dieta acrescida com 2,5\% de colesterol. Con (Controle); Sim (Simulação); ET (Esplenectomia total); LAV (Ligadura da artéria e veia esplênicas); ESTPI (Esplenectomia subtotal com preservação do pólo inferior). As colunas representam a média aritmética e desvio-padrão. * $p<0,05 e^{* *} p<0,01$ (Teste t de Student para amostras relacionadas).

\section{DISCUSSÃO}

No grupo em que se fez a ligadura simultânea da artéria e veia esplênicas haviam aderências mais firmes e freqüentes, envolvendo o baço e vísceras abdominais, o que confirma que a isquemia é um fator provocador de aderências ${ }^{39}$.

A formação de uma porção pediculada na porção inferior do órgão em 13 casos e na porção média em três casos do Grupo 4 foi semelhante ao tipo de lesão observada por Paulo et $\mathrm{l}^{31}$ ao realizarem ligadura simultânea da artéria e veia esplênicas e observarem o baço no $12^{\circ}$ dia pós-operatório. Touloukiam et al $^{37}$ realizando ligadura parcial do pedículo esplênico em ratos, observaram necrose do baço e regiões vizinhas com alteração transitória da função. Após dois meses, o baço se apresentou normal. Em nosso experimento, a ligadura dos vasos esplênicos produziu no baço necrose seguida de cicatrização da porção inferior ou média , conforme foi demonstrado. É possível que, logo após a ligadura dos vasos esplênicos, tenha ocorrido alteração nos níveis de lípides plasmáticos, mas em noventa dias houve manutenção dos níveis lipídicos conforme os nossos resultados.

Quando analisamos os níveis de lípides nos grupos não operado e simulado, verificamos que não houve alterações significantes entre eles no início do experimento, quando alimentados com dieta granulada. No final do experimento, os níveis de lípides não diferiram entre os Subgrupos 1A e 2A, e os Subrupos 1B e 2B. Os níveis de colesterol total foram significantemente maiores nos animais alimentados com dieta acrescida com 2,5\% de colesterol, à custa da VLDL. Esses resultados mostram que a operação simulada não interfere nos níveis de lípides, mas a dieta com colesterol, sim. A dietacontrole parece benéfica, porque os animais alimentados com ela tiveram diminuição do colesterol total à custa da LDL. A dieta com colesterol não parece benéfica, porque os animais alimentados com ela tiveram aumento significante do colesterol à custa da VLDL.

A análise das variações dos níveis de lípídes nos ratos submetidos à esplenectomia total mostrou que a retirada de todo o baço produz aumento desses lípides, confirmando as observações da literatura ${ }^{10-16,40}$. A dieta acrescida com 2,5\% de colesterol contribui para aumentar os níveis de colesterol nesses animais esplenectomizados, porque os níveis de colesterol total foram significantemente maiores no subgrupo 3B que no subgrupo 3A. De sorte que tanto a esplenectomia total quanto a dieta acrescida com 2,5\% de colesterol aumentam os níveis de colesterol total, LDL, VLDL e triglicérides. Aliás, já foi relatado em trabalhos clínicos ${ }^{10-12} \mathrm{e}$ experimentais ${ }^{13-16}$ que a esplenectomia provoca aumento do colesterol bem como a dieta ${ }^{14}$, e que os níveis de triglicérides em ratos esplenectomizados não se alteram ${ }^{16,40}$. Em nosso experimento houve aumento de triglicérides nos animais esplenectomizados. O aumento significante da LDL e triglicérides em animais esplenectomizados alimentados com dieta com colesterol foi também observado por Fatouros et $a l^{14}$ que usaram dieta com colesterol em ratos. Em nossa pesquisa, o aumento da LDL e dos triglicérides ocorreu nos animais esplenectomizados, independentemente do tipo de dieta

A análise das variações dos níveis de lípídes nos ratos submetidos à ligadura simultânea da artéria e veia esplênicas mostrou que essa operação não causa alterações significantes nos níveis desses lípides. Cumpre ressaltar que esses níveis foram significantemente menores que no grupo da esplenectomia total. Esses dados nos levam a admitir que o reamanescente esplênico da ligadura simultânea da artéria e veia esplênicas protege o animal da elevação dos níveis de colesterol tanto nos animais alimentados com dieta-controle quanto nos alimentados com dieta acrescida com 2,5\% de colesterol.

Se analisamos os níveis de lípides nos animais submetidos à esplenectomia subtotal com preservação do polo inferior, verificamos que essa operação manteve preservados os níveis de lípides de forma semelhante aos grupos não operado, simulado e ao da ligadura vascular, alimentados com a mesma dieta. Isso demonstra que o remanescente esplênico do polo inferior protege o animal de alterações lipídicas significantes. É bom ressaltar que a massa de tecido esplênico viável após a ligadura é maior que a massa do remanescente esplênico após esplenectomia subtotal $(\mathrm{p}<0,01)$. Apesar disso não houve diferença das variações dos níveis de colesterol entre os dois grupos de operações conservadoras sobre o baço. Bradshaw e Thomas ${ }^{41}$ relataram que, quanto maior o remanescente esplênico, maior a proteção contra a sepse, e calcularam em $25 \%$ a massa crítica de tecido esplênico residu- 
al para se ter função fagocitária normal. Esse relato é consenso da maioria dos autores que defendem que a massa crítica mínima necessária para manter a função esplênica deve ser superior a $25 \%$ da massa esplênica total ${ }^{42-45}$.Van Wick et al ${ }^{46}$, em trabalho experimental em ratos, consideraram necessária a manutenção de 1/3 do tecido esplênico total, para restaurar a função esplênica. Em nosso experimento o peso médio percentual do remanescente esplênico no grupo da ligadura simultânea da artéria e veia foi $49,21 \%$, e no grupo da esplenectomia subtotal com preservação do pólo inferior foi $37,26 \%$, massa suficiente para proteger o organismo das elevações dos lípides plasmáticos, conforme demonstramos.

Na tentativa de explicar o mecanismo pelo qual o baço interfere no metabolismo lipídico, Caligiuri et $a l^{47}$ sugeriram a participação do sistema imunológico mediado por linfócitos B no controle do LDL colesterol. Os linfócitos B seriam capazes de produzir anticorpos contra o LDL-colesterol-oxidado, e o complexo LDL-colesterol-oxidado mais o anticorpo seriam captados por receptores dos macrófagos do baço. Daí ocorreria a fagocitose com destruição do complexo tanto no nível local, nas placas de ateroma, quanto no nível sistêmico, no baço. A esplenectomia total levaria a um desequilíbrio na captação do complexo antígeno-anticorpo. Isso explicaria o aumento da LDL encontrado em animais esplenectomizados ${ }^{13-16,40}$. O aumento dos níveis de triglicérides e a queda dos níveis de HDL se devem provavelmente ao tipo de dieta utilizada ${ }^{14,16,40,48}$. Em nosso trabalho, os animais que se alimentaram de dieta com
$2,5 \%$ de colesterol tiveram aumento significante dos triglicérides, LDL e VLDL e queda da HDL no grupo simulado. No grupo da esplenectomia total houve aumento da LDL independentemente da dieta.

Em conclusão: 1- A esplenectomia total produz aumento significante do colesterol total, das frações LDL e VLDL e de triglicérides, tanto nos ratos alimentados com dieta-controle quanto nos alimentados com dieta acrescida com $2,5 \%$ de colesterol; 2- $\mathrm{O}$ aumento é mais significante nos animais alimentados com dieta acrescida com 2,5\% de colesterol; 3 - A ligadura simultânea da artéria e veia esplênicas e a esplenectomia subtotal com preservação do pólo inferior previnem contra as alterações dos níveis de lípides plasmáticos observadas em ratos submetidos à esplenectomia total, alimentados com dieta-controle ou acrescida com $2,5 \%$ de colesterol.

A partir dessas observações sugere-se que a retirada do baço produz alterações no metabolismo lipídico e que as operações conservadoras atenuam ou mesmo impedem essas alterações. Nesse sentido, algumas indagações devem ser feitas e necessitam ser investigadas. $\mathrm{O}$ que poderá ocorrer em animais esplenectomizados que se alimentarem de diferentes tipos de dieta? Quais seriam as repercussões das esplenectomias nas artérias de grosso e médio calibre no nível clínico e experimental? Quais seriam as influências das dietas e medicamentos em animais e em seres humanos esplenectomizados? Quais seriam os valores dos lípides plasmáticos em diferentes períodos de pós-operatório ?

\begin{abstract}
Background: To verify the effect on plasmatic lipid level of rats feed with control diet and diet added with $2.5 \%$ pure cholesterol after total splenectomy, ligature of the splenic vessels and partial splenectomy with preservation of the inferior pole. Methods: One hundred and eleven male Wistar rats weighting between 273 and $427 \mathrm{~g}$ aged 12 weeks, were randomly divided into 5 groups. Group $1(N=20)$ control group was not submitted to surgery; Group $2(N=20)$ submitted to manipulation of the spleen; Group $3(N=31)$ total splenectomy; Group $4(N=20)$ simultaneous ligature of the splenic artery and vein; Group $5(N=20)$ partial splenectomy with preservation of the inferior pole. Plasmatic lipids levels were measured and the animals divided in two subgroups according to the type of diet: subgroup A control diet, subgroup B had a $2.5 \%$ pure cholesterol added to the control diet. All animals were killed ninety days after the beginning of the experiment, following a new dosage of plasmatic lipids. Results: Animals submitted to total splenectomy, independently of any diet, showed significant increase $(p<0.05)$ in total cholesterol, LDL, VLDL and triglycerides. The increase of HDL was significant in the rats fed with control diet $(p<0.05)$ and non significant in the rats submitted to the diet with pure cholesterol $(p=0.29)$. The animals submitted to simultaneous ligature of vein and artery and to control diet did not show significant alteration of the plasmatic lipids. In the group submitted to diet added with pure cholesterol, we observed a significant increase $(p<0.05)$ in total cholesterol, VLDL and triglycerides, although the levels of HDL were the same. Animals submitted to partial splenectomy with preservation of the inferior pole and to control diet, did not show significant alterations ( $p<0.05)$ in total cholesterol, LDL, VLDL and triglycerides, but did in HDL ( $p<0.05)$. In those with diet with cholesterol we observed an increase in total cholesterol, LDL, VLDL and triglycerides but not in HDL. Conclusions: Total splenectomy leads to a significant increase of total cholesterol, LDL, VLDL and triglycerides, independently of the type of diet. The increase is more significant in the animals that received their diet with a $2.5 \%$ pure cholesterol. Simultaneous ligature of splenic artery and vein, partial splenectomy with preservation of the inferior pole protect against the alterations in the levels of plasmatic lipids observed in rats submitted to total splenectomy in both types of diet.
\end{abstract}

Key Words: Spleen/metabolism; splenectomy/adverse effects; Splenectomy/methods; Splenic artery; Splenic vein; Ligature.

\section{REFERÊNCIAS}

1. Green JB, Shackford SR, Sise MJ, et al. Late septic complications in adults following splenectomy for trauma: a prospective analysis in 144 patients. J Trauma. 1986;26(11):999-1004.
2. Di Cataldo A, Puleo S, Li Destri G, et al. Splenic trauma and overwhelming postsplenectomy infection. Br J Surg. 1987; 74(5):343-5.

3. Pimpl W, Dapunt O, Kaindl H, et al. Incidence of septic and thromboembolic-related deaths after splenectomy in adults. Br J Surg. 1989; 76(5):517-21. 
4. King H, Shumacker HB. Susceptibility to infection after splenectomy performed in infancy. Ann Surg.1952;136(2):23942.

5. O'Neal BJ, McDonald JC. The risk of sepsis in the asplenic adult. Ann Surg. 1981;194(6):775-8.

6. Morris DH, Bullock FD. The importance of the spleen in resistance to infection. Ann Surg.1919;70:513-21.

7. Grosfeld JL, Ranochak JE. Are hemisplenectomy and/or primary splenic repair feasible ? J Pediatr Surg.1976;11(3):419-24.

8. Goldthorn JF, Schwartz AD, Swift AJ, et al. Protective effect of residual splenic tissue after subtotal splenectomy. J Pediatr Surg. 1978;13(6D):587-90.

9. Andersson R, Alwmark A, Bengmark S. Outcome of pneumococcal challenge in rats after splenic artery ligation or splenectomy. Acta Chir Scand. 1986;152: 15-7.

10. Aviram M, Brook JG, Tatarsky I, et al. Increased low-density lipoprotein levels after splenectomy: a role for the spleen in cholesterol metabolism in myeloproliferative disorders. Am J Med Sci. 1986;291(1):25-8.

11. Sugihara T, Yawata Y. Observations on plasma and red cell lipids in hereditary spherocytosis. Clin Chim Acta. 1984;137(2):22732.

12. Robinette CD, Fraumeni JF. Splenectomy and subsequent mortality in veterans of the 1939-45 war. Lancet.1977;2(8029):127-9.

13. Asai K, Kuzuya M, Naito M, et al. Effects of splenectomy on serum lipids and experimental atherosclerosis. Angiology. 1988;39(6):497-504.

14. Fatouros M, Bourantas K, Bairaktari E, et al. Role of the spleen in lipid metabolism. Br J Surg. 1995;82(12):1675-7.

15. Paulo DNS, Silva AL. Lipídios plasmáticos após esplenectomia total e parcial em cães. Rev Col Bras Cir. 2001; 28(4):264-70.

16. Silva MM, Jamel N, Refinetti RA, et al. Papel do baço no perfil lipídico- Estudo Experimental.Arq Bras Cir Dig 2002;15:121-4.

17. Conti S. Splenic artery ligation for trauma. An alternative to splenectomy. Am J Surg. 1980;140(3):444-6.

18. Orozco H, Mercado MA, Martinez R, et al. Is splenectomy necessary in desvascularization procedures for treatment of bleeding portal hypertension ? Arch Surg.1998;133(1):36-8.

19. Abbas MA, Stone, WM, Fowl RJ, et al. Splenic artery aneurysms: two decades experience at Mayo Clinic. Ann Vasc Surg. 2002;16(4):442-9.

20. Witte CL, Corrigan JJ, Witte MH, et al. Splenic artery ligation in experimental hypersplenism. Surgery. 1976;80(5):581-5.

21. Sahin M, Tekin S, Aksoy F, et al. The effects of splenic artery ligation in an experimental model of secondary hypersplenism. $\mathrm{J}$ R Coll Surg Edinb.2000; 45(3):148-52.

22. Lin PW, Shan YS. Effects of splenectomy and splenic artery ligation on the portal pressure in portal hypertensive rats. J Surg Res. 1992;53(6):621-4.

23. Alwmark A, Bengmark S, Christensen P, et al. Increased susceptibility to pneumococci after ligation of the splenic artery in experimental hypersplenism. Eur Surg Res.1983;15(2):92-6.

24. Andersson R, Alwmark A, Bengmark S. Influence of dextran on pneumococcal septicemia in splenic artery-ligated or splenectomized rats. Res Exp Med.1987;187(6):423-7.

25. Tanaka T, Ichiba Y, Fujii Y, et al. New canine model of chronic pancreatitis due to chronic ischemia with incomplete pancreatic duct obstruction. Digestion. 1988;41(3):149-55.

26. Feigenberg Z, Abramovici A, Zer M, et al. Assessment of splenic function in dogs following arterial ligation and autotransplantation. Isr J Med Sci.1985; 21(7):579-83.

27. Ortyl W, Turowska B, Ciazynski M, et al. Anti-N antibodies after ligation of splenic artery in rabbits. Mater Med Pol.
1989;21(7):35-7.

28. Warshaw AL. Conservation of the spleen with distal pancreatectomy. Arch Surg.1988;123(5):550-3

29. Gramatica L, Lada PE, Gramática L, et al. Conservação do baço durante a pancreatectomia córporo-caudal. Rev Col Bras Cir. 1995;22(2):227-9.

30. Ueno T, Oka M, Nishihara K, et al. Laparoscopic distal pancreatectomy with preservation of the spleen. Surg Laparosc Endosc Percutan Tech. 1999;9(4): 290-3.

31. Paulo DNS, Paulo ICAL, Loureiro ER, et al. Viabilidade do baço de ratos após a ligadura simultânea da artéria e veia esplênica. Rev Col Bras Cir. 2005; 32(1):32-5.

32. Campos Christo MB. Esplenectomias parciais regradas. Hospital. 1959; 56: 645-50.

33. Petroianu A. Esplenectomia subtotal e anastomose esplenorrenal proximal, para o tratamento da hipertensão portal. Rev Bras Cir.1983;73(2):101-4.

34. Campos Christo MB. Bases anatômicas e experimentais das esplenectomias parciais. Rev Bras Cir. 1963;46(1):80-90.

35. Petroianu A. Estudo quantitativo da função fagocitária de macrófagos em baços íntegros e em remanescentes de esplenectomia subtotal, em mamíferos [dissertação]. Ribeirão Preto (SP): Universidade de São Paulo; 1993

36. Paulo DNS, Silva AL, Cintra LC, et al. Esplenectomia subtotal, em cães, com preservação do pólo inferior suprido por vasos do ligamento gastroesplênico. Rev Col Bras Cir.1999;(3)26:147-52.

37. Touloukian RJ, Dang CV, Caride VJ. Splenic function following experimental dearterialization injury in the suckling rat. J Pediat Surg. 1978;13(2):131-5.

38. Huu N. Territoires arteriéles de la rate. Presse Med.1956; 64:749.

39. Ellis H. The aetiology of post-operative abdominal adhesions. An experimental study. Br J Surg. 1962; 50:10-6

40. Jamel MJ, Refineti RA, Silva MM, et al. Papel do remanescente esplênico no perfil lipídico. ABCD Arq Bras Cir Dig. 2002;15:105-7.

41. Bradshaw PH, Thomas CG. Regeneration of splenic remnant after partial splenectomy in rats. J Surg Res.1982;32(2):176-81.

42. Cooney DR, Deatrth JC, Swanson SE, et al. Relative merits of partial splenectomy, splenic reimplantation, and immunization in preventing postsplenectomy infection. Surgery. 1979;86(4):561-9.

43. Livingston CD, Levine BA, Sirinek KR. Preservation of splenic tissue prevents postsplenectomy pulmonary sepsis following bacterial challenge. J Surg Res.1982;33(4):356-61.

44. Chappell JS . Splenic preservation. S Afr Med J. 1984;65(1): 12-4.

45. Pisters PW, Pachter HL. Autologus splenic transplantation for splenic trauma . Ann Surg.1994;219(3):225-35.

46. Van Wyck DB, Wiite MH, Wiite CL, et al. Critical splenic mass for survival from experimental pneumococcemia. J Surg Res.1980;28(1):14-7.

47. Caligiuri G, Nicoletti AP, Poirier B, et al. Protective immunity against atherosclerosis carried by $\mathrm{B}$ cells of hypercolesterolemic mice. J.Clin Invest. 2002;109(6):745-53.

48. Schmidt HH, Wagner S, Manns M. The spleen as a storage pool in lipid metabolism. Am J Gastroenterol. 1997;92(6):1072.

Endereço para correspondência:

Isabel Cristina Andreatta Lemos Paulo

Rua Santa Rita de Cássia, 777

Bairro de Lourdes

29042-753 - Vitória -ES

Fone: 27 3323-4827 / 27 3222-1545

Email: danilo.vix@zaz.com.br 